\title{
A CONTRAPOSIÇÃO ENTRE A NECESSIDADE DE APRIMORAMENTO DO PROFESSOR E A IMPOSIÇÃO DO SISTEMA EDUCACIONAL
}

\author{
Carmen Lúcia Dias, Natalie Perez Mendes, Ana Teresa S. Maia de Araújo, Amanda Delibório \\ Universidade do Oeste Paulista - Unoeste, Mestrado em Educação, Presidente Prudente, SP. E-mail: \\ kkaludias@gmail.com
}

\begin{abstract}
RESUMO
Este artigo tem por objetivo apresentar reflexões sobre a necessidade constante de aprimoramento e aperfeiçoamento do profissional professor e da imposição didática do sistema educacional que se contrapõe à essa busca pela inovação, reflexão e adequação mediante as necessidades de mudanças e constante aprendizado da categoria profissional para se opor à desvalorização dessa profissionalização. Para atingir tal objetivo, foi utilizada como metodologia a pesquisa bibliográfica em que autores e pesquisadores desta área propõem condições e necessidades dessa busca pelo desenvolvimento. Concluímos por meio dos conhecimentos e experiências transmitidos pelos autores na atual pesquisa, que existe a necessidade constante de aprimoramento e aperfeiçoamento do profissional educador, partindo do princípio de que a aprendizagem deve ser constante e contínua. Portanto, a imposição do governo estadual e federal no ciclo de aprendizagem, com material didático obrigatório, não deve ser favor impeditivo de reflexão e inovação.

Palavras-chave: Reflexão, Metodologia, Aprimoramento, Profissionalização, Inovação.
\end{abstract}

\section{THE CONTRAST BETWEEN THE NEED FOR IMPROVEMENT OF THE TEACHER AND THE IMPOSITION OF THE EDUCATIONAL SYSTEM}

\begin{abstract}
This article aims to present reflections on the need for constant improvement and enhancement of teacher professional and didactic imposition of the educational system that is opposed to this search for innovation, reflection and adaptation by the needs of change and constant learning of the profession to oppose the devaluation this professionalization. To achieve this goal, it was used as methodology the literature in which authors and researchers in this area propose conditions and needs of this quest for development. We concluded by means of knowledge and experience transmitted by the authors in the current research, that there is a constant need for improvement and enhancement of the professional educator, assuming that learning must be constant and continuous. Therefore, the imposition of the state and federal government in learning cycle, with mandatory teaching material, should not be an impediment for reflection and innovation.
\end{abstract}

Keywords: Reflection, Methodology, Improvement, Professionalization, Innovation. 


\section{INTRODUÇÃO}

Com o avanço do interesse pela educação nos países de primeiro mundo, temos observado com frequência os percalços que assolam a Educação no país. A falta de profissionais habilitados e até mesmo qualificados tem se intensificado diariamente e com isso o prejuízo para alunos estudantes das escolas públicas aumenta significativamente. Habilitados que acabam por abandonar a carreira profissional mediante empecilhos como: salários baixos, falta de reconhecimento profissional, excesso de indisciplina nas salas de aula, desestímulo até mesmo por parte do governo estadual com leis que prejudicam a atribuição de aulas e fixação do professor em escolas ou categorias, substituição por qualificados sem licenciatura e preparação para ministrar aulas.

No estado de São Paulo, a Lei Complementar 1093/2009 (Governador do Estado de São Paulo, José Serra) obriga o professor temporário a permanecer 40 dias sem participar da atribuição de aulas ao final do término do primeiro contrato e 200 dias ao final do término do segundo. E permite também, que pessoas com outras formações profissionais possam ministrar aulas na rede estadual de ensino, obtendo apenas 160 horas da disciplina em seu histórico escolar correlacionando seu conteúdo e qualificando-o como capaz para ensiná-la, mesmo sem nunca ter feito nenhuma licenciatura ou possuir nenhum prática com sala de aula.

Com isso, a metodologia tradicionalista, na qual um fala, o outro escuta, continua se sobressaindo nas escolas e mesmo com recursos que o governo estadual emprega, como material audiovisual, livros didáticos, projetos, ainda temos como prevalência o método expositivo e a avaliação em forma de prova como "carros chefes" na aprendizagem.

A aula expositiva é uma maneira de se ministrar aula, mas não é e não pode ser a única maneira. Se um profissional não concebe situações de aprendizagens diferentes para se respeitar diferentes estilos de linguagens em seus alunos e se as aulas que ministra não fazem o aluno o centro do processo de aprendizagem, o que a eles está impingindo com o nome de aula não é aula verdadeira. (ANTUNES, 2012, p. 23).

Contudo, diante da extensa e complexa problemática, ainda temos como fator relevante a imposição do sistema que se disfarça, através de um material denominado como "apoio". São apostilas impressas com conteúdos devidamente designados e selecionados, com base no Currículo do Estado de São Paulo, em que são expostos os conteúdos que devem ser trabalhados e as habilidades que o professor deve ter para desenvolvê-los. O "caderno do aluno" e "caderno do professor" são devidamente programados para serem desenvolvidos dentro do período letivo, dificultando o docente na tentativa de inovar ou utilizar suas aulas de forma mais dinâmica e 
variada, visto que o mesmo tem um cronograma que deve ser cumprido e este é periodicamente "fiscalizado" pelas Diretorias de Ensino. Cada situação de aprendizagem (capítulo) a ser desenvolvido, possui um prazo médio para sua conclusão, que varia de 2 a 4 horas-aula, para que o planejamento seja cumprido. Constam ainda, os conteúdo e temas que devem ser trabalhados, as competências e habilidades a serem desenvolvidas, e há sugestões de estratégias, recursos e avaliação.

É muito difícil para aqueles que estão fora das escolas melhorar a qualidade do que estas proporcionam [...] É a qualidade dos próprios professores e a natureza de seu compromisso para mudar o que determina a qualidade do ensino e da melhoria da escola. Os professores são, em geral, pobres realizadores das idéias dos outros. O desenvolvimento dos professores é, por conseguinte [...] uma precondição para o desenvolvimento do currículo. Sua compreensão, seu sentido de responsabilidade, seu compromisso de proporcionar de maneira efetiva experiência educativa para seus alunos, aumentam significativamente quando eles são os proprietários das idéias e os autores dos meios pelos quais essas idéias se traduzem em prática na sala de aula (MacDonald apud CONTRERAS, 2012, p. 143).

Neste contexto, o referente artigo tem por objetivo apresentar reflexões sobre a necessidade constante de aprimoramento e aperfeiçoamento do profissional professor e da imposição didática do sistema educacional que se contrapõe à essa busca pela inovação, reflexão e adequação mediante as necessidades de mudanças e constante aprendizado da categoria profissional para se opor à desvalorização dessa profissionalização.

\section{DESENVOLVIMENTO}

"O principal objetivo da educação é criar pessoas capazes de fazer coisas novas e não simplesmente repetir o que as outras gerações fizeram." Jean Piaget

Observa-se que manter o aluno centrado no conteúdo da aula já não é uma tarefa tão fácil como há tempos parecia. Hoje, é preciso que a didática do professor seja criativa, interativa e participativa. O método expositivo não possui a mesma eficácia que outrora.

Como se sabe, o adulto, na concepção tradicional, é considerado como um homem acabado, 'pronto' e o aluno um 'adulto em miniatura', que precisa ser atualizado. O ensino, em todas as suas formas, nessa abordagem, será centrado no professor. Esse tipo de ensino volta-se para o que é externo ao aluno: o programa, as disciplinas, o professor. O aluno apenas executa prescrições que lhe são fixadas por autoridades exteriores. (MIZUKAMI, 1986, p. 8). 
Com a tecnologia, a internet, as informações e conhecimentos são muito mais acessíveis, bem como os aparelhos para utilizá-los, tornando estritamente relevante que o professor esteja, acima de tudo, preparado e tenha domínio sobre o conteúdo a ser apresentado. Esse conteúdo precisa estar vinculado a uma dinâmica que capte a atenção dos alunos e seja interessante para a realidade dos mesmos. A prática consegue transformar esse conhecimento em realidade de forma mais clara e de fácil compreensão. A esta prática, deve estar atrelada ao trabalho de educação das consciências, ou seja, a reflexão.

[...] entre a teoria e a atividade prática transformadora se insere um trabalho de educação das consciências, de organização dos meios materiais e planos concretos de ação; tudo isso como passagem indispensável para desenvolver ações reais, efetivas. Nesse sentido, uma teoria é prática na medida que se materializa, através de uma série de mediações, o que antes só existia idealmente, como conhecimento da realidade ou antecipação ideal de sua transformação. (SAVIANI, 1999, p. 82).

Desta forma, o professor precisa estar preparado para questionamentos e instigá-los, auxiliando os alunos na construção do conhecimento. Realizar esses processos, a partir de um parâmetro imposto, torna esse trabalho extremamente difícil. É preciso que o professor esteja sempre buscando novos conhecimentos, ou seja, em constante formação para que consiga utilizar-se de sua criativa preparação para tornar esse aprendizado adequado, interessante e ao mesmo tempo reflexivo. É o professor que deve possuir esse discernimento para determinar a forma de fazê-lo e como selecioná-lo em meio a um emaranhado de influências externas, partindo sempre da sua realidade atual, não classificando-a como similar a todas as outras, mas entendendo e compreendendo que ela é única e diferenciada. Parte daí, a necessidade de uma formação permanente do professor que o auxiliará nesta difícil tarefa diária:

[...] A formação permanente do professor deve ajudar a desenvolver um conhecimento profissional que lhe permita: avaliar a necessidade potencial e a qualidade da inovação educativa que deve ser introduzida constantemente nas instituições; desenvolver habilidades básicas no âmbito das estratégias de ensino em um contexto determinado, do planejamento, do diagnóstico e da avaliação; proporcionar as competências para ser capazes de modificar as tarefas educativas continuamente, em uma tentativa de adaptação à diversidade e ao contexto dos alunos; comprometer-se com o meio social. Tudo isso supõe uma formação permanente que desenvolva processos de pesquisa colaborativa para o desenvolvimento da organização, das pessoas e da comunidade educativa que as envolve. (IMBERNÓN, 2011, p. 72)

São os próprios profissionais do ensino (ou pelo menos deveria ser) que, em última instância, decidem a forma com que planejam suas aulas, por meio dos quais as tentativas de 
influência externa são transformadas em práticas que nem sempre têm muito a ver com a essência das mudanças pretendidas. No entanto, não é apenas uma questão de impossibilidade. É também uma questão de conviç̧ão que se deduz dos argumentos da racionalidade prática. “[...] Só quem pratica e só na prática podem-se realizar os valores educativos enquanto tratam de perguntar sobre seu significado". (CONTRERAS, 2012, p. 144).

Como poderemos nós, professores, conhecer o que se deve fazer? Uma resposta possível é que teremos de receber instruções em forma de currículo e de especificações sobre os métodos pedagógicos. Pessoalmente rejeito essa idéia. A educação é um aprendizado no contexto de uma busca da verdade. A verdade não pode estar definida pelo Estado, nem sequer por meio de processos democráticos: um controle estrito do currículo e dos métodos pedagógicos nas escolas é equivalente ao controle totalitário da arte. Alcançar a verdade por meio da educação é um assunto de juízo profissional em cada situação concreta, e os professores de educação ou os administradores não podem nos indicar o que devemos fazer. As recomendações variarão em cada caso. Não necessitaremos de um médico se o que este nos indicar for um tratamento prescrito pelo Estado ou sugerido por seu professor, sem sequer nos ter examinado e diagnosticado previamente. (STENHOUSE apud CONTRERAS, 2012, p. 144).

Enfatizemos ainda o que SCHON nos reforça: "a prática profissional desenvolvida da perspectiva reflexiva não é uma prática que se realiza abstraindo-se do contexto social do qual ocorre". (SCHON, 2000).

Os professores nem querem nem podem limitar seus afazeres ao que lhe for dito. Os especialistas em diferentes matérias já tentaram [...]. Os administradores tentaram. Os legisladores tentaram. Entretanto, os professores não são operários de uma linha de montagem e não se comportarão assim [...]. os professores praticam uma arte. Os momentos de escolha sobre o que fazer, como fazer, com quem e a que ritmo surgem centenas de vezes ao longo de um dia e com cada grupo de estudantes. Nenhuma ordem ou instituição pode ser formulada de modo que controle esse tipo de julgamento e comportamento artístico, dadas as demandas de freqüentes decisões instantâneas sobre a forma de enfrentar uma situação continuamente [...]. Portanto, os professores tem de se envolver no debate, na deliberação e na decisão sobre o que e como ensinar. Tal implicação constitui a única linguagem em que pode surgir um conhecimento adequado para a sua arte. Sem essa linguagem assim, os professores não só viverão as decisões como imposições, mas acharão que a inteligência não pode atravessar a distâncias entre as generalizações de instruções meramente expostas e as particularidades dos momentos de ensino. É necessária a participação no debate, na deliberação e na escolha tanto para o aprendizado do que necessita como para a vontade de fazê-lo. (SCHWAB apud CONTRERAS, 2012, p. 142). 
Mediante tais situações, percebemos a problemática do profissional professor tornar-se consciente da necessidade cumulada com o desestímulo, de melhorar constantemente sua formação, abrindo-se a novas perspectivas e focando a educação baseada nas realidades sociais e numa constante prática reflexiva, tornando essa troca aprender-ensinar-aprender com os alunos, base para novas reflexões, compreendendo que é de sua responsabilidade ser essa mola propulsora, os alunos necessitam de motivação para o aprendizado, a partir de seus conhecimentos pessoais e aprendam de forma a sentirem-se capacitados para uma constante discussão sobre cada assunto, ao invés da constante submissão nesse processo de aprender e crescer.

A instrução é essencial ao homem e quanto mais instruídos somos, melhor agimos e, portanto constitui um erro pensar que uma educação avançada exclui instruções, mas erro maior ainda é acreditar que a arte de ensinar se confunde com a arte de instruir. (ANTUNES, 2012, p. 29).

Compete aos professores a análise das situações, a escolha das opções, a tomada de decisões e a disposição para juntos lutarem e assumirem riscos a fim de que o desespero não seja convincente e a esperança seja viável. Esperança de buscar sempre o melhor, o espaço de possibilidades a caminho da liberdade. Pelo menos, a liberdade de ser e de estar na profissão professor. (ABDALLA, 2006, p. 44).

Partindo desta realidade, para formação de professores reflexivos e pesquisadores, precisamos nos ater a obstáculos como local de formação e principalmente, condições de exercer essa prática reflexiva na rotina real escolar.

[...] o que pôs novamente em pauta de discussão as questões organizacionais, o projeto pedagógico das escolas, a importância do trabalho coletivo, as questões referentes à autonomia dos professores e das escolas; as condições de trabalho, de carreira, de salário, de profissionalização de professores; a identidade epistemológica (quais saberes lhe são próprios?); os processos de formação dessa identidade, incluindo a vida, a história, a trajetória pessoal e profissional; as novas (e complexas) necessidades colocadas às escolas (e aos professores) pela sociedade contemporânea das novas tecnologias, da informação e do conhecimento, do esgarçamento das relações sociais e afetivas, da violência, da indisciplina, do desinteresse pelo conhecimento, gerado pelo reconhecimento de formas de enriquecimento que independem do trabalho; das novas configurações do trabalho e do desemprego, requerendo que os trabalhadores busquem constantemente requalificação através de cursos de formação contínua etc. (SCHON, 2012, p. 25).

Libâneo (2012) explicita como atualmente está assentada a metodologia de ensino das escolas. Ele a divide em quatro referências básicas: 
$\checkmark$ Ligação entre a cultura elaborada e a cultura experienciada dos alunos;

$\checkmark$ Uma pedagogia do pensar, que promova o aprender a pensar e o aprender a aprender;

$\checkmark$ Uma pedagogia diferenciada;

$\checkmark$ Ensino e prática de valores e atitudes na escola e na sala de aula.

Para Libâneo (2012), a organização do ensino depende de condições imprescindíveis que devem ser propiciadas pela escola como projeto pedagógico-curricular, plano de trabalho bem definidos, coerentes, com os quais os professores se sintam identificados, orientação metodológica segura por parte da coordenação pedagógica, assistência permanente aos professores, materiais de estudos e didáticos, sistema de avaliação e acompanhamento dos alunos, práticas de gestão participativa, entre outros.

Contudo, essa esquematização, perfeita e eficiente aos olhos superficiais de uma realidade escolar conturbada, não nos permite perceber quão grande são os problemas dessa funcionalidade que ocorre de forma perfeita e coerente, no papel. Complementa Stenhouse apud Contrera (2012):

[...] Que objetivos devem ser estes: os dos Estados, os de quem desenvolve o currículo, os do professor ou os do aluno? Todos os alunos de uma mesma classe devem ter os mesmos objetivos? Como se deve diferenciar os objetivos? Como examinar ou avaliar se há grupos alternativos de objetivos de um mesmo currículo? A realidade é que nossas salas de aula e ensino variam ano a ano e outro tanto ocorre em qualquer outra classe em qualquer ano [...] [O modelo de objetivos não aumenta] nossa capacidade de compreender nossas aspirações, porque não se enfrenta adequadamente a situação multivariada da classe. Em resumo, não é a melhor base para o desenvolvimento do professor (p.130).

Com a atual crise na educação e a constante falta de professores, essa contextualização está longe de acontecer. A realidade prática da vida escolar está atrelada ao despreparo de profissionais que ocupam a cadeira do professor e a recursos para utilização que qualificam a classe de alunos como homogênea, bem como o ambiente escolar, sua administração e coordenação entre outras funcionalidades que fazem parte desta realidade educacional.

Libâneo conclui ainda:

São requeridas, também, disposições e condições da parte dos professores, tais como: domínio dos conteúdos e adequação destes aos conhecimentos que o aluno já possui, a seu desenvolvimento mental, a suas características socioculturais e suas diferenças; o domínio das metodologias de ensino correspondentes aos conteúdos; clareza nos objetivos propostos, acentuando o desenvolvimento de capacidades cognitivas e de habilidades de pensar e 
aprender; planos de ensino e de aula; uma classe organizada, alunos motivados e sem tensão; levar em conta a prática do aluno, saber planejar atividades em que ele desenvolva sua atividade mental; dominar procedimentos e instrumentos de avaliação de aprendizagem. (LIBÂNEO, 2012, p. 495).

Essa visão homogênea e abastecida de soluções práticas para a metodologia de ensinoaprendizagem infelizmente não ocorre na prática diária. Muitos desses fatores, tornam-se utópicos quando o Estado se impõe contradizendo suas teorias. Profissionais distintos de conhecimentos básicos para a educação, muitos deles adquiridos nas disciplinas presentes nos cursos de licenciatura, torna a prática desfalcada e limitada. A programação didática e pronta, impedindo espaços de criatividade, vivacidade e reflexão em sala de aula, acaba por nos mostrar o quanto ainda precisa ser feito, ser modificado, para que esse sistema educacional funcione de forma coerente e natural, transformando jovens em homens responsáveis e questionadores diante das verdades impostas. Esse currículo deve ser objeto de indagação da mesma maneira que deve se reconstruir na própria ação do professor. Para Stenhouse, a pesquisa sobre a própria docência surge a partir da necessidade de colocar à prova, de submeter ao escrutínio da prática, as idéias expressas em uma proposta curricular.

O currículo é um meio para estudar os problemas e os efeitos da realização de qualquer linha definida de ensino [...]. A qualidade única de cada classe supõe que toda proposta - inclusive no plano escolar - em sua própria sala de aula. O ideal é que a especificação do currículo inspire a pesquisa e um programa de desenvolvimento pessoal por parte do professor, mediante o qual ele aumente progressivamente a compreensão de seu próprio trabalho e aperfeiçoe assim seu próprio ensino. (Stenhouse apud Contrera, 2012, p. 133).

Diante dessa problemática fica a questão: o que podemos fazer para mudar isso? Essa mudança é responsabilidade de todos ou só compete àqueles que se encontram em posições de tomadas de decisões no âmbito escolar?

\section{CONCLUSÃO}

Através dos conhecimentos e experiências transmitidos pelos autores na atual pesquisa, podemos observar a necessidade constante de aprimoramento e aperfeiçoamento do profissional educador, partindo do princípio de que a aprendizagem deve ser constante e contínua. Observamos também que esse aprimoramento deve ser acima de tudo reflexivo, trazendo 
questionamentos e novas idéias, criando e recriando uma nova ótica que será introduzida na sociedade através daqueles que estiverem envolvidos de uma forma ou de outra nesse processo.

Portanto, a imposição do governo estadual e federal no ciclo de aprendizagem, com material didático obrigatório, não deve ser favor impeditivo de reflexão e inovação. É considerável a dificuldade que se tem para esse trâmite, mas é preciso empenho e esforço por parte do professor e da escola, como sistema organizacional e órgão mediador de educação, na desenvoltura desse processo enriquecedor de aprendizagem, onde ambas as partes saem vitoriosas. O professor, aperfeiçoando-se encontrará novas formas de trabalho que favorecem a cada dia o sistema de aprendizagem.

\section{REFERÊNCIAS}

ABDALLA, M.F.B. O senso prático de ser e estar na profissão. São Paulo: Cortez, 2006.

ANTUNES, C. Professores e professauros: reflexões sobre a aula e práticas pedagógicas diversas. Petrópolis, RJ: Vozes, 2012.

CONTRERAS, J. A autonomia de professores. 2.ed. São Paulo: Cortez, 2012.

LIBÂNEO, J. C., OLIVEIRA, J. F., TOSCHI, M.S. Educação escolar: políticas, estrutura e organização. São Paulo: Cortez, 2012.

MIZUKAMI, M.G.N. Ensino: as abordagens do processo. São Paulo: EPU, 1986. SÃO PAULO (ESTADO) SECRETARIA DE EDUCAÇÃO. Lei Complementar n.o 1093, de 16 de julho de 2009. Governo do Estado de São Paulo. José Serra, 2009. Disponível em: <http:// www. al.sp.gov.br/repositorio/legislacao/lei.complementar/2009/lei.complementar-109316.07.2009.html>. Acesso em: 29 jul. 2015.

SAVIANI, D. Escola e democracia. Campinas: Autores associados, 1999.

SCHON, D. A. Educando o profissional reflexivo: um novo design para o ensino e a aprendizagem. Porto Alegre: Artmed, 2000. 